See Article page 20.

\section{Commentary: Staying put: Supraclavicular intra-aortic balloon pump placement}

\author{
Walker M. Blanding, MD, ${ }^{a}$ Paul Brocklebank, BS, ${ }^{b}$ \\ and Arman Kilic, $\mathrm{MD}^{\mathrm{a}}$
}

Traditional femoral intra-aortic balloon pump (IABP) placement has long been plagued by the inability of patients to ambulate while on support. While axillary insertion allows ambulation, it is complicated in upwards of $40 \%$ of cases by balloon migration, driveline kinking, and IABP malfunction, all of which are believed to be worsened by patient movement. ${ }^{1,2}$ In this edition of JTCVS Techniques, Song and Jeevanandam ${ }^{3}$ present their percutaneous supraclavicular subclavian approach to IABP placement with the use of a 24-cm wire-reinforced sheath.

Percutaneous supraclavicular subclavian IABP placement can be performed in the operating room or catheterization laboratory through the use of ultrasound and micropuncture for initial arterial access. Angiogram is then performed, the sheath is upsized to 9 Fr with the distal tip in the descending aorta just above the left mainstem bronchus, and the IABP is placed through a standard sheath over wire technique. The balloon and sheath are then secured to the patient using a silk suture, making sure to instill some laxity in the system to prevent migration with normal movement. Song's group typically uses left-sided access to reduce the risk of cerebral embolism if patient anatomy is suitable. The authors note anecdotal evidence of less kinking and migration due to the stiffer sheath with the distal tip sitting only a few centimeters proximal to the balloon in the descending aorta. In terms of removal,

\footnotetext{
From the ${ }^{\mathrm{a}}$ Division of Cardiothoracic Surgery, and ${ }^{\mathrm{b}}$ College of Medicine, Medical University of South Carolina, Charleston, SC

Disclosures: Dr Kilic reported Medical Advisory Board (Medtronic, Inc). Dr Blanding and Mr Brocklebank reported no conflicts of interest.

The Journal policy requires editors and reviewers to disclose conflicts of interest and to decline handling or reviewing manuscripts for which they may have a conflict of interest. The editors and reviewers of this article have no conflicts of interest.

Received for publication April 27, 2021; revisions received April 27, 2021; accepted for publication April 29, 2021; available ahead of print May 4, 2021.

Address for reprints: Arman Kilic, MD, Division of Cardiothoracic Surgery, Medical

University of South Carolina, 30 Courtenay Dr, MSC 295, Suite BM279,

Charleston, SC 29425 (E-mail: kilica@musc.edu).

JTCVS Techniques 2021;8:23-4

2666-2507

Copyright (C) 2021 Published by Elsevier Inc. on behalf of The American Association for Thoracic Surgery. This is an open access article under the CC BY-NC-ND license (http://creativecommons.org/licenses/by-nc-nd/4.0/).

https://doi.org/10.1016/j.xjtc.2021.04.034
}

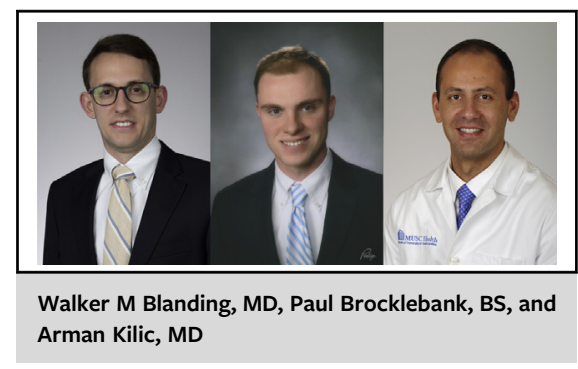

CENTRAL MESSAGE

A supraclavicular subclavian approach for IABP placement may offer a reliable technique for ambulatory support that may mitigate some shortcomings of traditional approaches.

the balloon and sheath can be removed at bedside in the intensive care unit. While this group typically uses an ANGIO-SEAL device or manual pressure, their technique should be amenable to other percutaneous closure devices such as Perclose; balloon and sheath exchange can be achieved through standard techniques.

The 2018 heart allocation policy change increased the priority of patients with IABPs. ${ }^{4}$ Since then, the percentage of patients bridged with IABPs has more than tripled. ${ }^{5}$ As an ever-increasing number of patients with heart failure receive IABPs, it is important to improve the complication profile and patient burden of this method of support. Song and Jeevanandam offer a single and straightforward alternative to traditional axillary access that may mitigate some of the technical issues associated with shorter sheaths and transfemoral access, particularly in those in whom longerterm support is expected as a bridge to transplantation. We look forward to more data comparing this technique with their historic cohort of axillary access.

\section{References}

1. Estep JD, Cordero-Reyes AM, Bhimaraj A, Trachtenberg B, Khalil N, Loebe M, et al. Percutaneous placement of an intra-aortic balloon pump in the left axillary/ subclavian position provides safe, ambulatory long-term support as bridge to heart transplantation. JACC Heart Fail. 2013;1:382-8.

2. Russo MJ, Jeevanandam V, Stepney J, Merlo A, Johnson EM, Malyala R, et al Intra-aortic balloon pump inserted through the subclavian artery: a minimally invasive approach to mechanical support in the ambulatory end-stage heart failure patient. J Thorac Cardiovasc Surg. 2012;144:951-5.

3. Song T, Jeevanandam V. Technique of percutaneous supraclavicular subclavian intra-aortic balloon pump placement. J Thorac Cardiovasc Surg Tech. 2021;8: $20-2$. 
4. OPTN/UNOS policy notice proposal to modify the Adult Heart Allocation System [Internet]. 2018;1-38. Available at: https://optn.transplant.hrsa.gov/media/2028/ thoracic_policynotice_201612.pdf. Accessed April 7, 2021.
5. Kilic A, Mathier MA, Hickey GW, Sultan I, Morell VO, Mulukutla SR, et al Evolving trends in adult heart transplant with the 2018 heart allocation policy change. JAMA Cardiol. 2021;6:159-67. 